\title{
Simultaneous Optimal Placement of DGs and Fixed Capacitor Banks in Radial Distribution Systems using BSA Optimization
}

\author{
Meera Shareef Syed \\ PG Scholar, Department of E.E.E \\ Sir C R Reddy College of Engineering
}

\author{
Satish Kumar Injeti \\ Associate Professor, Department of E.E.E \\ Sir C R Reddy College of Engineering
}

\begin{abstract}
Nowadays the research on the integration of DG's and Capacitor banks in radial distribution system is going on, to meet the increased electricity demand and to improve the technical aspects like power loss reduction, voltage profile improvement etc., where the major concerns are finding the optimal sizing of DG's and Capacitor banks and their locations. This paper presents application of new optimization algorithm; Backtracking Search Algorithm (BSA) to solve the optimal placement of both DG and fixed capacitor banks in order to reduce the power loss and improve voltage profile of distribution system. A detailed performance analysis is carried out on 33-bus and 69-bus radial distribution system to demonstrate the effectiveness of the proposed algorithms and the results are compared with the GA/PSO, ICA/GA and Analytical approach which are available in the literature.
\end{abstract}

\section{Keywords}

Distribution Generation (DG), Fixed Capacitor bank, Backtracking search Algorithm (BSA).

\section{INTRODUCTION}

Nowadays a wide range of research is going on the distribution system as it is the final link between the bulk power system and the consumers. Distribution system generally operates at low voltage and high currents, results in more amounts of power loss and poor voltage profile when compared to Transmission system. From the studies it is approximated that the share of Distribution losses in total power generated is $13 \%$ [1]. The electricity demand is increasing day-to-day leads to the further increment in power losses and voltage drops. Such amount of high power losses limits the line capacity (thermal limits) and poor voltage profile causes the voltage instability of the system. Therefore the concern is not only about the improvements of technical aspects but also to meet the future electricity demand for the existing distribution system by maintaining the line capacity and the voltage stability.

Installation of DG's in the radial distribution network at the load centers can improve the voltage profile and reduce the real power losses to the significant effect as it controls the active and reactive power flows in the distribution primary lines. As the DGs can inject both real and reactive power it can reduce transmission and distribution capacity release which can be utilized for increased future demand of electricity. In decentralized electricity market installation of DGs encourages the Distribution network operators, as it reduces the amount of energy taken from the transmission side. With growing concerns among the environmental impacts majorly contributed by the centrally dispatched generations, renewable energy DG sources can provide most viable alternative to the utilities. A " $2 / 3$ rule" analytical method is suggested for the installation of DG by [8]. Satish Kumar Injeti et al. suggested simulated annealing (SA) method [9] for the sizing of multiple DGs and their allocation is done by using loss sensitivity factors. An ABC method is proposed for the optimal DG unit's location, size and power factor by [10], for the reduction of active power loss. PSO is applied for optimal placement of multiple DGs in distribution system with varying power load models by [11]. Optimal placement of DG is done by considers uncertainties using fuzzy numbers and is solved by a hybrid NSGA-II in [12]. A detailed analysis of DG placement is given by [13], which describes the different algorithms and methods of their approaches for the loss reduction and voltage profile improvement.

Due to the limited DG's sources and high implementation cost, we can't have a wide usage of DG sources. Therefore it is necessary to use another parallel element with DG which having low implementation cost, to improve the technical aspects like power loss reduction, voltage profile and power factor improvement. Since capacitor supports reactive power and improves the above mentioned technical aspects, combined optimal placement of DG and capacitor for improving the same amount of technical aspects requires less amount of real power injection by the DG against optimal placement of DG only which reduces the implementation cost of DG. Hence the simultaneous placement capacitor and DG gives the optimal operational economics of power system. Sayyid Mohssen Sajjadi et al. [14] proposed Memetic alogorithm (MA) for optimal sizing of DG's and capacitors and their corresponding location are given by voltage stability index. Mohammad H. Moradi, et al. [15-16] proposed GA/PSO and ICA/GA for the optimal sizing of DG's \& capacitor banks and their locations. He considered a multi objective function for this optimization problem and explores economical advantages for corresponding technical improvements. S. Gopiya Naik et al. [17] proposed an analytical approach for optimal sizing of a DG and a capacitor and their corresponding location are given by loss sensitivity factor for loss minimization.

Back Tracking Search Algorithm (BSA), a population based evolutionary algorithm was proposed by Pinar Civicioglu in 2013 [18]. In this paper BSA optimization algorithm is utilized to minimize the power loss by determining the optimal locations and sizes of DG's and Fixed Capacitor banks in radial distribution system. In order to validate the effectiveness of the proposed algorithms, they have tested on IEEE-33 and IEEE-69 radial bus systems and the results are 
compared with existing algorithms. The Standard Backward/Forward Sweep power flow method suggested in [19-20] is used for the load flow analysis.

The rest of this paper is organized as follows. Section 2 gives the objective function formulation, Section 3 gives the overview of proposed algorithm, Section 4 presents the result analysis and Section 5 outlines the conclusions

ask that authors follow some simple guidelines. In essence, we ask you to make your paper look exactly like this document. The easiest way to do this is simply to download the template, and replace the content with your own material.

\section{OBJECTIVE FUNCTION FORMULATION \\ 2.1 Objective Function}

Installation of DG's injects real and reactive power \& Capacitors injects reactive power causes altering of both real and reactive power flows in radial distribution system which results in the reduction of power losses and voltage profile improvement. The objective function is considered as power loss minimization which requires finding of optimal sizes and locations of both DG's and fixed capacitor banks subjected to some operational constraints. Mathematically the objective function is formulated as

Minimize $\quad P_{T, \text { loss }}=\sum_{i=1}^{n-1}\left|J_{i}\right|^{2} * \operatorname{re}\left(Z_{i}\right)$

Where $\mathrm{P}_{\mathrm{T}, \text { loss }}$ is the total active power loss, $\mathrm{n}$ is the number of buses, $Z_{i}$ is the impedance of the $i^{\text {th }}$ branch and $\mathrm{J}_{\mathrm{i}}$ is the branch current of the $\mathrm{i}^{\text {th }}$ branch

Branch currents are obtained from the results after performing Standard backward/forward sweep power flow [21] using eq. (2).

$$
J=B I B C * I
$$

Where $\mathrm{J}$ represents the branch current matrix, BIBC represents the bus injected branch current matrix and I represent the nodal current matrix.

$I_{i}=\left(\frac{\left(P_{i}-P_{D G i}\right)+j *\left(Q_{i}-\left(Q_{c i}+Q_{D G i}\right)\right)}{V_{i}}\right)^{*}$

Where $P_{i}, Q_{i}$ are the active and reactive power load at the $i^{\text {th }}$ bus, $\mathrm{P}_{\mathrm{DGi}}, \mathrm{Q}_{\mathrm{DGi}}$ are the real and reactive power of DG's injected at the $i^{\text {th }}$ bus, $Q_{c i}$ is the reactive injected by the capacitor at the $\mathrm{i}^{\text {th }}$ bus and $\mathrm{V}_{\mathrm{i}}$ is the voltage at $\mathrm{i}^{\text {th }}$ node.

\subsection{Constraints}

The objective function is subjected to following constraints:

- The voltage magnitude must kept within the specified limits at each bus:

$V_{\min } \leq V \leq V_{\max }$

Where $\mathrm{V}_{\min }, \mathrm{V}_{\max }$ are the lower and upper limits of bus voltage, respectively.

- From practical limitation, maximum compensation by using DG's is limited to the total active power demand.

$\sum_{i=1}^{N_{D G}} P_{D G i} \leq \sum_{j=1}^{N_{l}} P_{D}(j)$

Where $\mathrm{N}_{\mathrm{DG}}$ is the number of DG's, $\mathrm{N}_{l}$ is the number of load buses and $P_{D}(j)$ is the reactive power demand of load at bus $j$.

- From practical limitation, maximum compensation by using capacitor bank is limited to the total reactive power demand.
$\sum_{i=1}^{N_{c}} Q_{c}(i)+\sum_{i=1}^{N_{D G}} Q_{D G i} \leq \sum_{j=1}^{N_{l}} Q_{D}(j)$

Where $\mathrm{N}_{l}$ is the number of load buses and $\mathrm{Q}_{\mathrm{D}}(\mathrm{j})$ is the reactive power demand of load at bus $\mathrm{j}$.

- Capacitors are available in discrete sizes so shun capacitors to be dealt with multiple integers of the smallest capacitor size available and it may be mathematically expressed as

$Q_{c}(i)=L Q_{s}$

Where, $\mathrm{Q}_{\mathrm{s}}$ is the smallest capacitor size available and $\mathrm{L}$ is an integer multiple.

All material on each page should fit within a rectangle of $18 \mathrm{x}$ $23.5 \mathrm{~cm}$ (7" x 9.25"), centered on the page, beginning $2.54 \mathrm{~cm}$ (1") from the top of the page and ending with $2.54 \mathrm{~cm}(1 ")$ from the bottom. The right and left margins should be $1.9 \mathrm{~cm}$ $\left(.75^{\prime \prime}\right)$. The text should be in two $8.45 \mathrm{~cm}(3.33 ")$ columns with a $.83 \mathrm{~cm}(.33 ")$ gutter.

\section{BACKTRACKING SEARCH ALGORITHM (BSA)}

Please BSA is a population-based iterative EA designed to be a global minimiser. SA can be explained by dividing its functions into five processes as is done in other EAs: initialization, selection-I, mutation, crossover and selection-II.

Algorithm General Structure of BSA:

1) Initialization

Repeat

2) Selection-I

Generation of trail population
(3) Mutation
(4) Crossover

End

5) Selection-II

Until stopping conditions are met.

\section{1) Initialization}

BSA initializes the population P with Eq. (8):

$\mathrm{P}_{\mathrm{ij}} \sim \mathrm{U}\left(\mathrm{low}_{\mathrm{j}}, \mathrm{up}_{\mathrm{j}}\right)$

for $\mathrm{i}=1,2,3, \ldots, \mathrm{N}$ and $\mathrm{j}=1,2,3, \ldots, \mathrm{D}$, where $\mathrm{N}$ and $\mathrm{D}$ are the population size and the problem dimension, respectively, $\mathrm{U}$ is the uniform distribution and each $\mathrm{P}_{\mathrm{i}}$ is a target individual in the population $\mathrm{P}$

\section{2) Selection-I}

BSA's Selection-I stage determines the historical population oldP to be used for calculating the search direction. The initial historical population is determined using Eq. (9):

$\operatorname{oldP}_{\mathrm{ij}} \sim \mathrm{U}\left(\mathrm{low}_{\mathrm{j}}, \mathrm{up}_{\mathrm{j}}\right)$

(9)

BSA has the option of redefining oldP at the beginning of each iteration through the 'if-then' rule in Eq. (10):

If $\mathrm{a}<\mathrm{b}$ then oldP: $=\mathrm{P} \mid \mathrm{a}, \mathrm{b} \sim \mathrm{U}(0,1)$,

Where : $=$ is the update operation. Eq. (10) ensures that BSA designates a population belonging to a randomly selected previous generation as the historical population and 
remembers this historical population until it is changed. Thus, BSA has a memory.

After oldP is determined, Eq. (11) is used to randomly change the order of the individuals in oldP:

oldP: $=$ permuting $($ oldP $)$.

The permuting function used in Eq. (11) is a random shuffling function.

\section{3) Mutation}

BSA's mutation process generates the initial form of the trial population Mutant using Eq. (12).

Mutant $=\mathrm{P}+\mathrm{F}$. (oldP $-\mathrm{P})$

In Eq. (12), F controls the amplitude of the search-direction matrix (oldP - P). Because the historical population is used in the calculation of the search-direction matrix, BSA generates a trial population, taking partial advantage of its experiences from previous generations. This paper uses the value $\mathrm{F}=$ $3 *^{*}$ rndn, where, rndn $\sim \mathrm{N}(0,1)$ ( $\mathrm{N}$ is the standard normal distribution)

\section{4) Crossover}

BSA's crossover process generates the final form of the trial population $T$. The initial value of the trial population is Mutant, as set in the mutation process. Trial individuals with better fitness values for the optimization problem are used to evolve the target population individuals. BSA's crossover process has two steps. The first step calculates a binary integer-valued matrix (map) of size $\mathrm{N}^{*} \mathrm{D}$ that indicates the individuals of $\mathrm{T}$ to be manipulated by using the relevant individuals of $P$. If $\operatorname{map}_{n, m}=1$, where $n \epsilon\{1,2,3, \ldots, N\}$ and $\mathrm{m} €\{1,2,3, \ldots, D\}, T$ is updated with $\mathrm{T}_{\mathrm{n}, \mathrm{m}}:=\mathrm{P}_{\mathrm{n}, \mathrm{m}}$.

\section{5) Selection-II}

In BSA's Selection-II stage, the $\mathrm{T}$ is that have better fitness values than the corresponding $\mathrm{P}$ is are used to update the $\mathrm{P}$ is based on a greedy selection. If the best individual of $\mathrm{P}\left(\mathrm{P}_{\text {best }}\right)$ has a better fitness value than the global minimum value obtained so far by BSA, the global minimizer is updated to be $\mathrm{P}_{\text {best }}$, and the global minimum value is updated to be the fitness value of $\mathrm{P}_{\text {best }}$. The structure of BSA is quite simple; thus, it is easily adapted to different numerical optimization problems and the Figure 1 represents the flowchart for BSA.

\section{RESULT ANALYSIS}

The performance and effectiveness of the proposed algorithm for power loss minimization has been tested on 33-bus and 69-bus radial distribution system for six cases. The six different cases are shown in the Table 1. A number of trails on the performance of the applied algorithms have been carried out on the test systems to determine the most suitable parameters

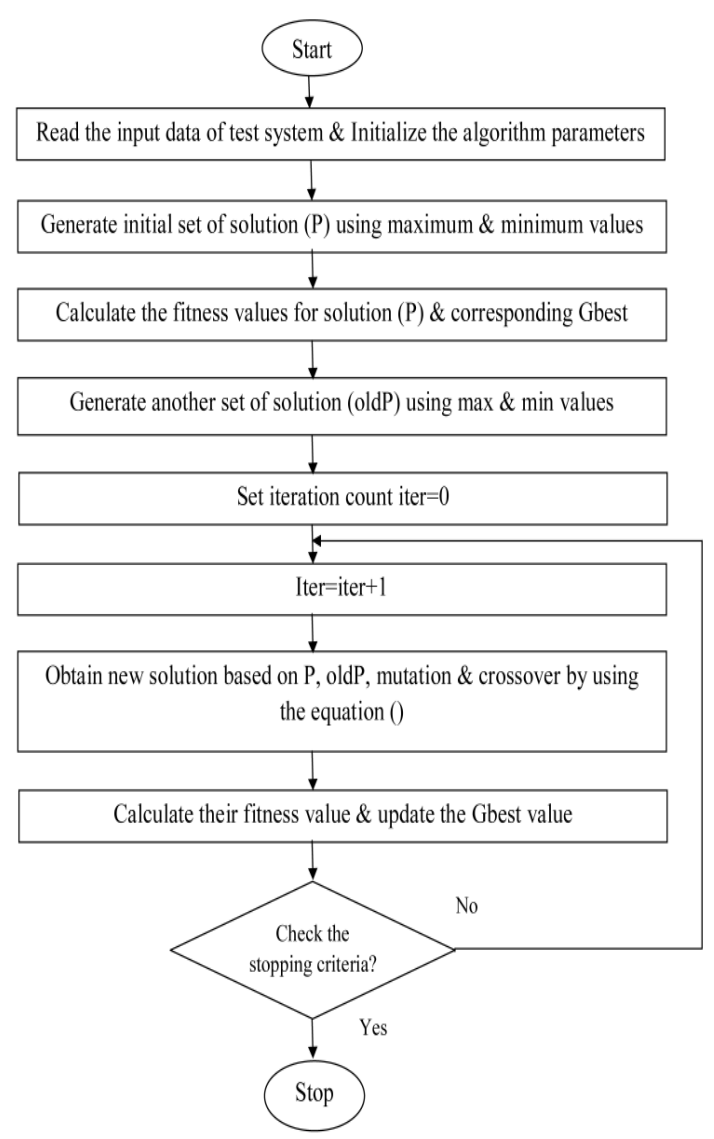

Fig.1 Flow chart for BSA

Table 1 Six Different Cases

\begin{tabular}{|c|c|}
\hline Cases & $\begin{array}{c}\text { Type of sources used for } \\
\text { compensation }\end{array}$ \\
\hline 1 & Single DG only \\
\hline 2 & Single DG and capacitors \\
\hline 3 & Two DGs only \\
\hline 4 & Two DGs and capacitors \\
\hline 5 & Three DGs only \\
\hline 6 & Three DGs and capacitors \\
\hline
\end{tabular}

Table 2 Tuned Parameters of BSA

\begin{tabular}{|c|c|c|c|}
\hline Algorithm & Parameter & Description & Value \\
\hline \multirow{7}{*}{ BSA } & $\mathrm{N}$ & $\begin{array}{c}\text { Population of } \\
\text { size }\end{array}$ & 150 \\
\cline { 2 - 4 } & $\mathrm{D}$ & $\begin{array}{c}\text { Dimension of } \\
\text { the search } \\
\text { space }\end{array}$ & $\begin{array}{c}\text { Case } \\
\text { dependent }\end{array}$ \\
\cline { 2 - 4 } & $\mathrm{M}$ & Mix rate & 0.8 \\
\hline & maxitr & $\begin{array}{c}\text { Maximum } \\
\text { number of } \\
\text { cycles }\end{array}$ & 150 \\
\hline
\end{tabular}

In this work, the tuned parameters of BSA are given in Table 2. The entire simulation is developed in MATLAB R2010a software and the simulations are carried on a computer with Intel(R) Core(TM) i5-2450M CPU @ 2.50GHz, 4 GB RAM. 


\subsection{3-Bus Test System Numerical Results}

The 33-bus test case consists of a main feeder and 3 subfeeders (laterals) radial distribution system as shown in Figure 2. The data of the system is obtained from [16]. The total load of the system is $3715 \mathrm{~kW}$ and $2300 \mathrm{kVAR}$. The rated voltage of the system is $12.66 \mathrm{kV}$. After an initial load flow run using Backward/Forward Sweep method for an uncompensated system, the active power loss is $210.9823 \mathrm{KW}$ and maximum $\&$ minimum voltages are 1.0 p.u and 0.9038 p.u respectively.
To observe the effectiveness of the proposed algorithm, its results are compared with the other techniques like GA/PSO, ICA/GA and Analytical Approach. Table 3 shows, the optimal locations and sizes of DG's \& capacitors, DG's operating power factors, total real power injected, total active power loss and percentage of loss reduction for BSA algorithms for six different cases respectively. From Table 3 it is also observed that the reduction of power loss in case2, case4 \& case6 is more when compared to case 1 , case 3 \& case 5 .

Table 3 Comparison of Results of BSA for 33-Bus System 6 for Cases

\begin{tabular}{|c|c|c|c|c|c|c|}
\hline Parameters & $\begin{array}{l}\text { Single DG } \\
\text { placement }\end{array}$ & $\begin{array}{c}\text { Single DG \& } \\
\text { Capacitors } \\
\text { placement }\end{array}$ & $\begin{array}{l}\text { Two DG } \\
\text { placement }\end{array}$ & $\begin{array}{l}\text { Two DG \& } \\
\text { Capacitors } \\
\text { placement }\end{array}$ & $\begin{array}{l}\text { Three DG } \\
\text { placement }\end{array}$ & $\begin{array}{c}\text { Three DG \& } \\
\text { Capacitors } \\
\text { placement }\end{array}$ \\
\hline $\begin{array}{c}\text { Optimal locations of } \\
\text { DG's }\end{array}$ & 30 & 11 & 14,30 & 30,14 & $30,12,24$ & $25,14,30$ \\
\hline $\begin{array}{c}\text { Optimal sizes of } \\
\text { DG's(KW) }\end{array}$ & 1000 & 1075 & 570,954 & 933,590 & $1000,848,938$ & $1000,749,1000$ \\
\hline Power factor & 0.866 & 0.866 & $0.866,0.866$ & $0.866,0.866$ & $0.866,0.866,0.866$ & $0.866,0.866,0.866$ \\
\hline $\begin{array}{c}\text { Total Real Power } \\
\text { Injected(KW) }\end{array}$ & 1000 & 1075 & 1524 & 1523 & 2786 & 2749 \\
\hline $\begin{array}{c}\text { Optimal locations for } \\
\text { capacitors }\end{array}$ & -------- & $23,32,30$ & ---------------- & $2,24,11,33$ & |------------------------ & 33,2 \\
\hline $\begin{array}{c}\text { Optimal sizes of } \\
\text { capacitors(KVAR) }\end{array}$ & -------- & $150,150,900$ & ---------------- & $150,150,150,450$ & |------------------------ & 300,300 \\
\hline $\begin{array}{c}\text { Active power loss in } \\
\mathrm{KW}\end{array}$ & 95.8117 & 65.7545 & 44.2993 & 32.8524 & 17.51 & 13.8543 \\
\hline$\%$ Loss reduction & 54.58 & 68.83 & 79.00 & 84.42 & 91.69 & 93.43 \\
\hline Elapsed time & 31.8177 & 20.450268 & 17.391571 & 19.812635 & 18.444371 & 23.430 \\
\hline
\end{tabular}

Table 4 Comparison of Results with Existing Methods for 33-Bus

\begin{tabular}{|c|c|c|c|}
\hline \multirow[t]{2}{*}{ Parameters } & \multicolumn{2}{|c|}{ Proposed Methods } & Existing Methods \\
\hline & BSA & GA/PSO [15] & ICA/GA[15] \\
\hline Optimal locations of DG's & $25,14,30$ & $14,25,30$ & $13,24,30$ \\
\hline Optimal sizes of DG's(KW) & $1000,749,1000$ & $674,670,835$ & $\begin{array}{l}794.8,1069,102 \\
9\end{array}$ \\
\hline Power factor & $0.866,0.866,0.866$ & $0.88,0.85,0.90$ & $0.905,0.90,0.81$ \\
\hline Optimal locations for capacitors & 33,2 & $12,30,32$ & $8,18,30$ \\
\hline $\begin{array}{l}\text { Optimal sizes of } \\
\text { capacitors(KVAR) }\end{array}$ & 300,300 & $150,450,150$ & $150,150,300$ \\
\hline Active power loss in KW & 13.8543 & 17.01 & 14.01 \\
\hline$\%$ Loss reduction & 93.43 & 91.93 & 93.35 \\
\hline Elapsed time & 23.430 & N/A & N/A \\
\hline
\end{tabular}

Table 5 Comparison of Results with Analytical Approach for 33-Bus

\begin{tabular}{|l|c|c|}
\hline \multicolumn{1}{|c|}{ Parameters } & \multicolumn{2}{c|}{ Proposed Methods Existing method } \\
\cline { 2 - 3 } & BSA & 18 \\
\hline Optimal locations of DG's & 11 & 800 \\
\hline Optimal sizes of DG's(KW) & 1075 & 0.85 \\
\hline Power factor & 0.866 & 33 \\
\hline Optimal locations for capacitors & $23,32,30$ & 800 \\
\hline Optimal sizes of capacitors(KVAR) & $150,150,900$ & 89.72 \\
\hline Active power loss in KW & 65.7545 & 57.47 \\
\hline \% Loss reduction & 68.83 & N/A \\
\hline Elapsed time & 20.450268 & .17] \\
\hline
\end{tabular}

In cases 2, 4 \& 6 amount of MVA injection by DG's is same as in cases $1,3 \& 5$ respectively, but difference in loss reduction of for BSA 14.25, $5.42 \& 1.74$ between the cases is observed. So the simultaneous placement of DG's and capacitors has more power loss reduction than the only DG placement. Figure 3 shows the comparison of power loss reduction of BSA for six cases. To check the efficiency of the proposed algorithms the results are compared with existing algorithms GA/PSO, ICA/GA and Analytical Approaches which is shown in Table 4 and Table 5. From Table 4 it is observed that the proposed algorithm gives the better result when compared with the GA/PSO and ICA/GA algorithms, the proposed method BSA gives the best result with a loss reduction of $93.43 \%$. From Table 5 it is observed that both the proposed algorithms give the better result when compared with the Analytical Approach, the proposed methods BSA gives the best result with a loss reduction of $69.42 \%$. 

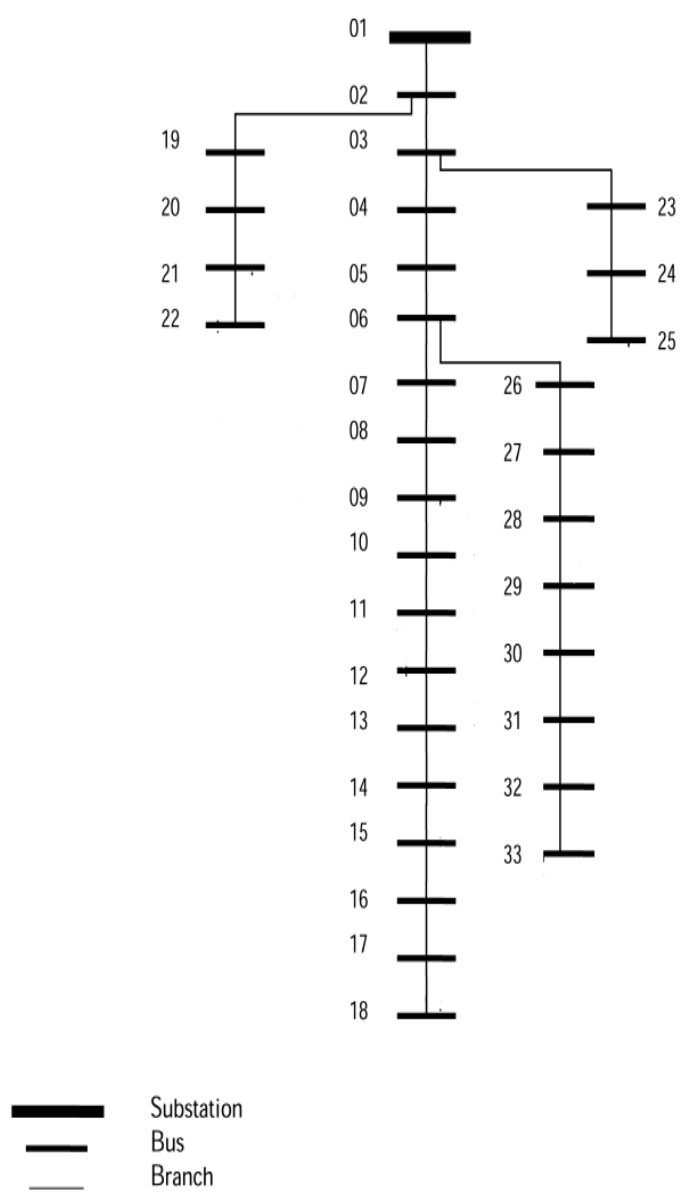

Fig.2 Single line diagram of 33-bus radial distribution system

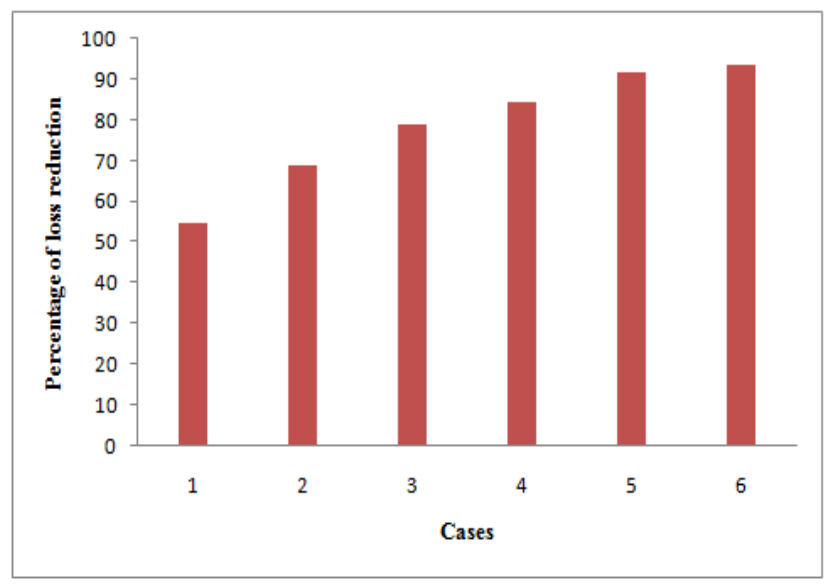

Fig.3 Comparison of loss reduction of BSA for six cases (33bus)

\subsection{9-Bus Test System Numerical Results}

The 69-bus test case consists of a main feeder and 7 sub-feeders (laterals) radial distribution system as shown in Fig 4. The data of the system is obtained from [22]. The total load of the system is $3801 \mathrm{~kW}$ and $2694 \mathrm{kVAR}$. The rated voltage of the system is $12.66 \mathrm{kV}$. After an initial load flow run using Backward/Forward Sweep method for an uncompensated system, the active power loss is $224.8949 \mathrm{KW}$ and maximum \& minimum voltages are 1.0 p.u and 0.9092 p.u respectively. To observe the effectiveness of the proposed algorithms, their results are compared with the other techniques like GA/PSO and ICA/GA. Table VI shows, the optimal locations and sizes of DG's \& capacitors, DG's operating power factors, total real power injected, total active power loss and percentage of loss reduction for BSA algorithm for six different cases respectively. From Table VI it is also observed that the reduction of power loss in case2, case 4 \& case 6 is more when compared to case 1 , case $3 \&$ case 5 . In cases 2, $4 \& 6$ amount of MVA injection by DG's is same as in cases $1,3 \& 5$ respectively, but difference in loss reduction of for BSA $10.758,1.581 \& 0.932$ between the cases is observed. So the simultaneous placement of DG's and capacitors has more power loss reduction than the only DG placement. Fig 5 shows the comparison of power loss reduction of BSA for six cases. To check the efficiency of the proposed algorithms the results are compared with existing algorithms GA/PSO and ICA/GA which is shown in Table VII. From Table VII it is observed that the proposed algorithm gives the better result when compared with the GA/PSO and ICA/GA algorithms.

\subsection{Convergence and Voltage Profile Analysis}

The convergence and voltage profile graphs for all the six cases are shown in Figure 6 and Figure 7 for the two test systems. From the convergence graphs it is observed that, for the case 6 of 33-bus system BSA reached to best solution at 95th generation and in case 6 of 69 -bus system it reached the better solution at 39 th generation.

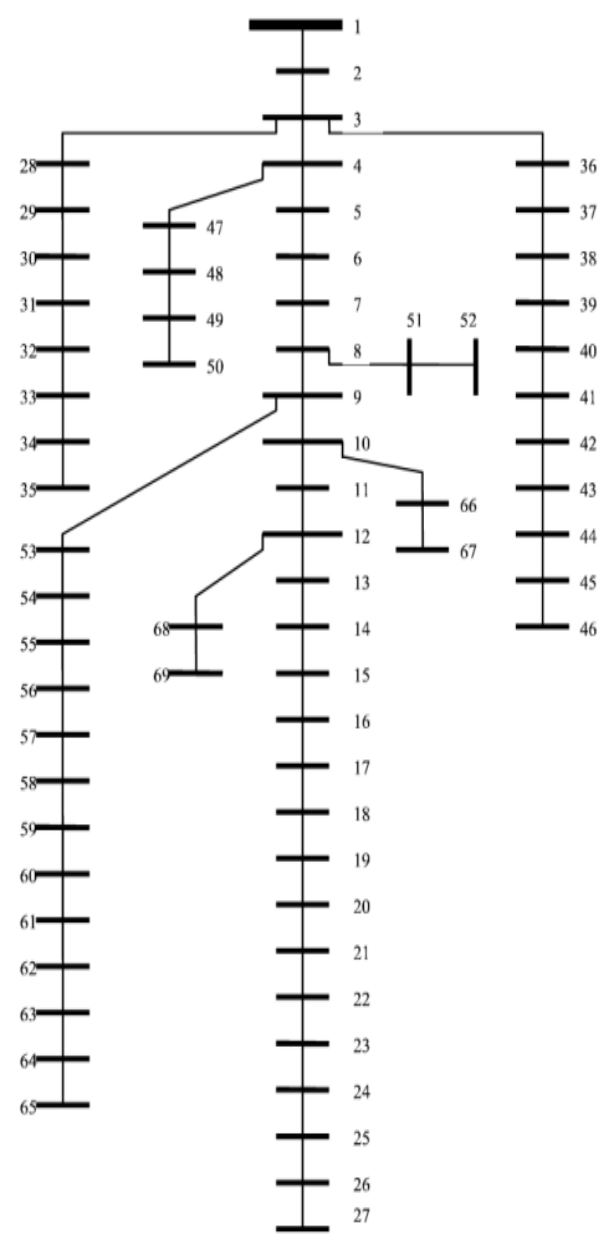

Fig.4 Single line diagram of 69-bus radial distribution system 
Table 6 Comparison of Results of BSA for 69-Bus System 6 for Cases

\begin{tabular}{|c|c|c|c|c|c|c|}
\hline Parameters & $\begin{array}{l}\text { Single DG } \\
\text { placement }\end{array}$ & $\begin{array}{c}\text { Single DG \& } \\
\text { Capacitors } \\
\text { placement }\end{array}$ & $\begin{array}{c}\text { Two DG } \\
\text { placement }\end{array}$ & $\begin{array}{l}\text { Two DG \& } \\
\text { Capacitors } \\
\text { placement }\end{array}$ & $\begin{array}{l}\text { Three DG } \\
\text { placement }\end{array}$ & $\begin{array}{c}\text { Three DG \& } \\
\text { Capacitors } \\
\text { placement }\end{array}$ \\
\hline $\begin{array}{l}\text { Optimal locations of } \\
\text { DG's }\end{array}$ & 61 & 61 & 61,23 & 62,9 & $61,20,62$ & $19,22,61$ \\
\hline $\begin{array}{l}\text { Optimal sizes of } \\
\text { DG's(KW) }\end{array}$ & 1000 & 1000 & 1357,164 & 1350,170 & $767,514,100$ & $294,219,1768$ \\
\hline Power factor & 0.866 & 0.866 & $0.866,0.866$ & $0.866,0.866$ & $\begin{array}{c}0.866,0.866,0.8 \\
66\end{array}$ & $\begin{array}{l}0.866,0.866 \\
\quad, 0.866\end{array}$ \\
\hline $\begin{array}{l}\text { Total Real Power } \\
\text { Injected(KW) }\end{array}$ & 1000 & 1000 & 1521 & 1521 & 2281 & 2281 \\
\hline $\begin{array}{l}\text { Optimal locations for } \\
\text { capacitors }\end{array}$ & $\begin{array}{c}----------- \\
-\end{array}$ & $62,22,61$ & --------------- & $16,2,57$ & ---------------- & $7,2,3$ \\
\hline $\begin{array}{l}\text { Optimal size of } \\
\text { capacitor(KVAR) }\end{array}$ & $\begin{array}{c}-------------- \\
-\end{array}$ & $450,300,150$ & -------------- & $450,150,300$ & ---------------- & $450,300,150$ \\
\hline Active power loss in $\mathrm{KW}$ & 66.9526 & 42.7798 & 30.2357 & 26.69 & 9.7196 & 7.6047 \\
\hline$\%$ Loss reduction & 70.229 & 80.987 & 86.55 & 88.131 & 95.678 & 96.61 \\
\hline Elapsed time & 61.434655 & 90.053564 & 68.035410 & 69.090415 & 67.115659 & 62.518903 \\
\hline
\end{tabular}

Table 7 Comparison of Results with Existing Methods for 69-Bus

\begin{tabular}{|c|c|c|c|}
\hline \multirow[t]{2}{*}{ Parameters } & \multicolumn{2}{|c|}{ Proposed Methods } & Existing Methods \\
\hline & BSA & CA/GA[15] & SO [15] \\
\hline Optimal locations of DG's & $19,22,61$ & $18,61,64$ & $11,18,61$ \\
\hline Optimal sizes of DG's(KW) & $294,219,1768$ & $422,1184,305$ & $490.1,386,1693$ \\
\hline Power factor & $0.866,0.866,0.866$ & $0.85,0.88,0.83$ & $0.99,0.98,0.91$ \\
\hline Optimal locations for capacitors & $7,2,3$ & $11,49,61$ & $21,61,64$ \\
\hline Optimal sizes of capacitors(KVAR) & $450,300,150$ & $150,150,600$ & $300,1050,300$ \\
\hline Active power loss in KW & 7.6047 & 8.02 & 31.6 \\
\hline$\%$ Loss reduction & 96.61 & 96.43 & 85.94 \\
\hline Elapsed time & 62.518903 & N/A & N/A \\
\hline
\end{tabular}

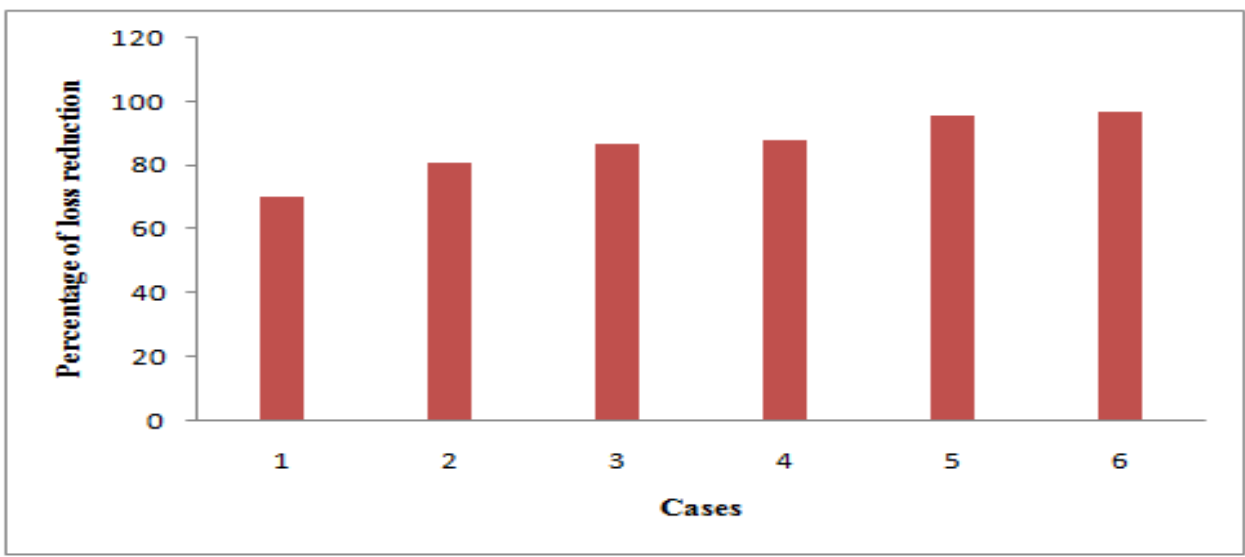

Fig.5 Comparison of loss reduction of BSA for six cases (69-bus 

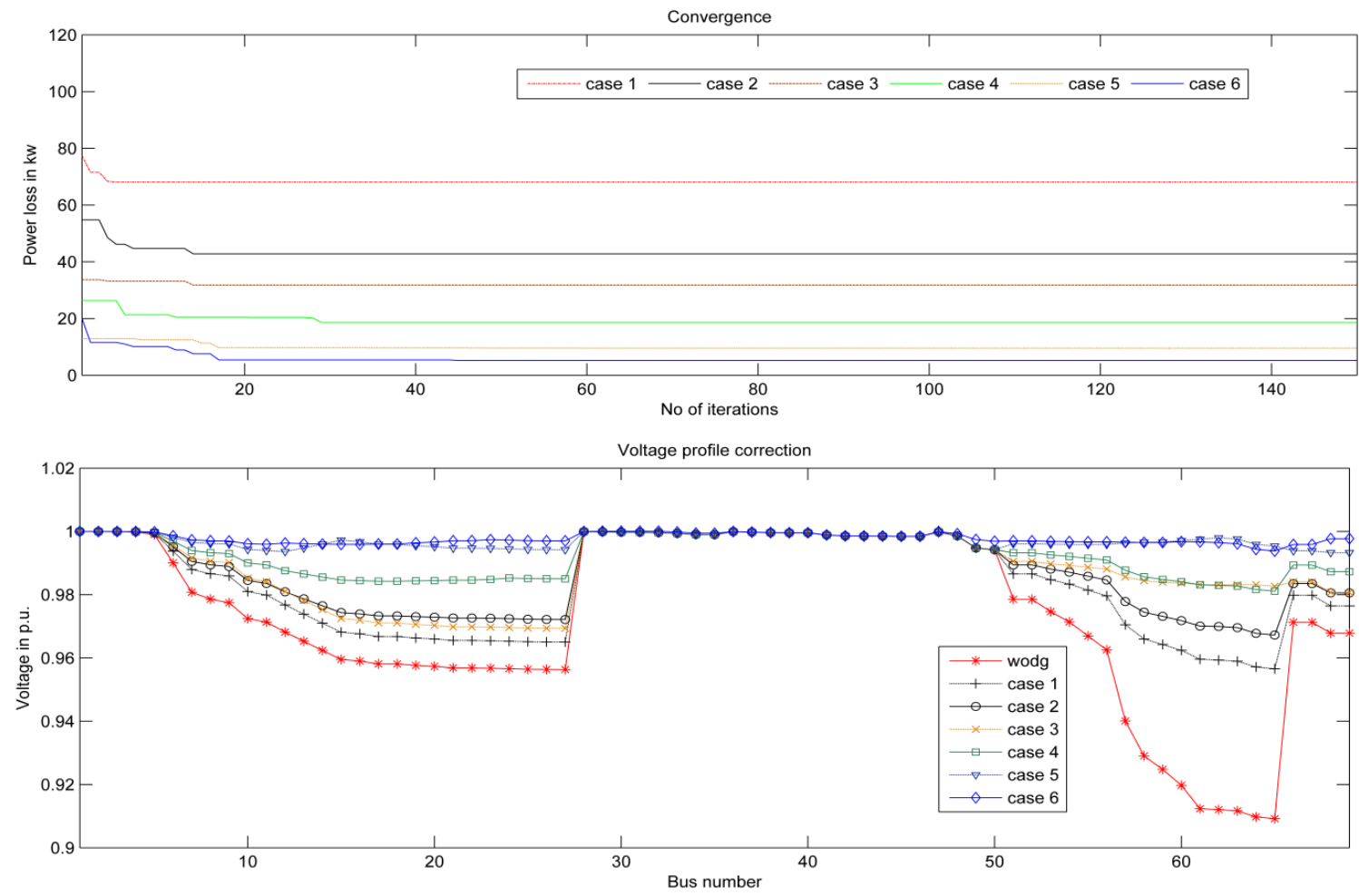

Fig.6 Convergence and voltage profile of six cases of BSA for 33-bus
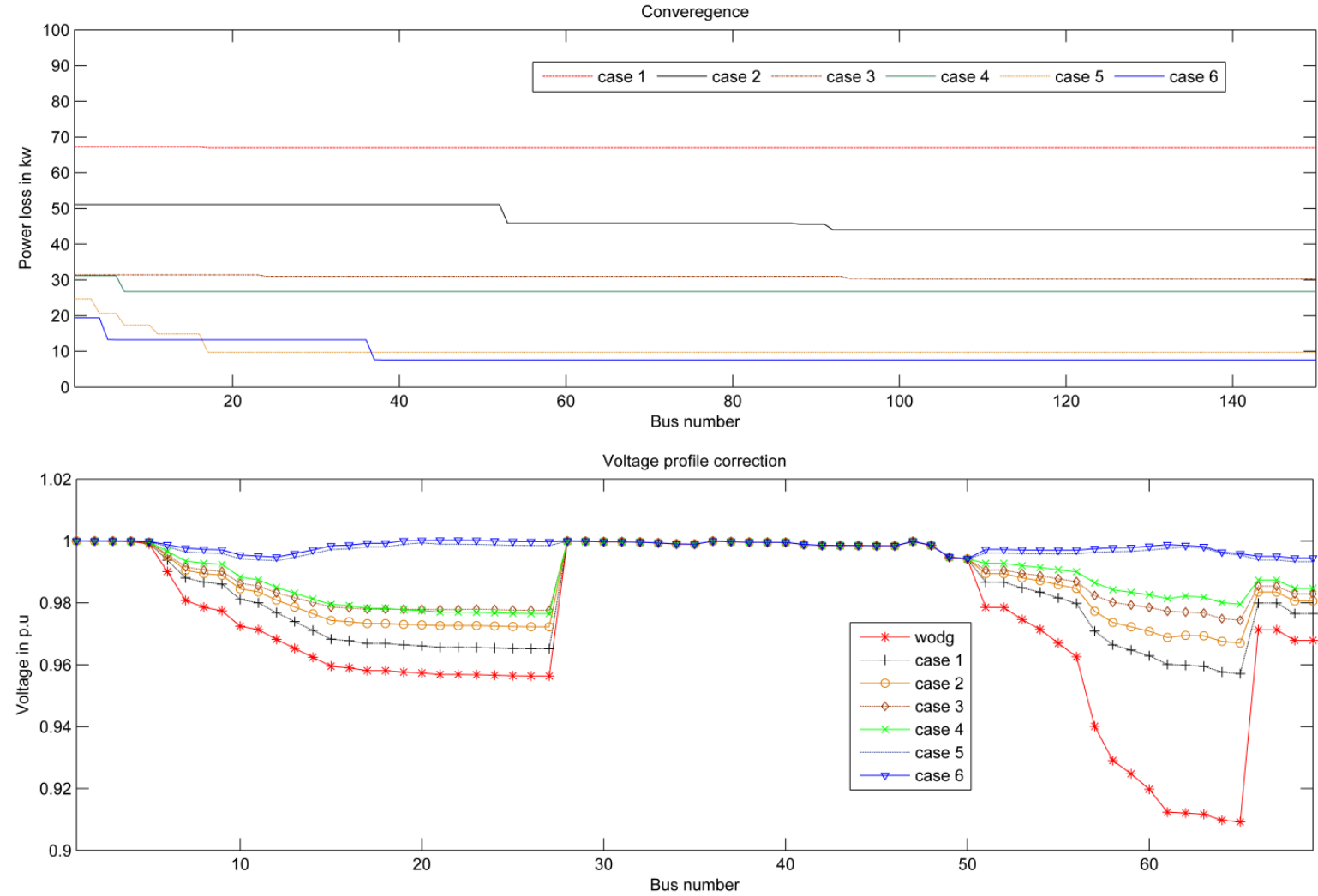

Fig.7 Convergence and voltage profile of six cases of BSA for 69-bus 


\section{CONCLUSION}

In this paper, a new algorithm has been proposed for the simultaneously optimal placement of DGs and capacitors in a distribution system. This algorithm is applied on six different cases; the result shows that, cases with simultaneous placement of DG and capacitor have much improvement of voltage profile and power loss reduction when compared with cases of only DG placement. From the results, it is observed that the percentage of power loss reduction is improving as the number of DG's is increasing from 1 to 3 , but the rate of improvement of percentage power loss reduction is decreasing from $1 \mathrm{DG}$ to 3DG's. Among all the six cases percentage of loss reduction is more in case 6 . The results of BSA algorithm with comparison of existing algorithms show that the performance of BSA is better than GA/PSO, ICA/GA and Analytical Approach.

\section{REFERENCES}

[1] Ng HN, Salama MA, Chikhani AY. Classification of capacitor allocation techniques. IEEE Trans Power Deliv 2000; 15(1):387-92.

[2] J.V.Schmill," optimum size and location of shunt capacitors on distribution feeders",IEEE Trans. On Power Apparatus and System.vol. 84, pp. 825-832, sep. 1965.

[3] Prakash K, Sydulu M. Particle swarm optimization based capacitor placement on radial distribution systems. IEEE power engineering society general meeting; 2007, pp. 15

[4] Raju MR, Murthy KVSR, Avindra KR. Direct search algorithm for capacitive compensation in radial distribution systems. Int J Elect Power Energy Syst., 2012; 42(1), pp.24-30.

[5] Sneha S, Provas Kumar R. Optimal capacitor placement in radial distribution systems using teaching learning based optimization. Int. J Elect Power Energy Syst., 2013, 54, pp. 387-398.

[6] Iman Ziari, Gerard Ledwich, Arindam Ghosh. A new technique for optimal allocation and sizing of capacitors and setting of LTC. Electrical Power and Energy Systems 46 (2013) 250-257.

[7] Sirjani R, Azah M, Shareef H. Heuristic optimization techniques to determine optimal capacitor placement and sizing in radial distribution networks: a comprehensive review. PRZEGLA D ELEKTROTECHNICZNY (Elect. Rev.), 2012, 88(7a), pp.1-7.

[8] H. L. Willis, "Analytical methods and rules of thumb for modeling DG-distribution interaction," in Proc. IEEE Power Eng. Soc. Summer Meeting, Jul. 2000, pp. 16431644.

[9] Satish Kumar Injeti, N. Prema Kumar. A novel approach to identify optimal access point and capacity of multiple DGs in a small, medium and large scale radial distribution system. Electrical Power and Energy Systems 45 (2013) 142-151

[10] F. S. Abu-Mouti and M. E. El-Hawary, "Optimal distributed generation allocation and sizing in distribution systems via artificial bee colony algorithm," IEEE Trans. Power Del., vol. 26, no. 4, pp. 2090-2101, Oct. 2011.

[11] A. M. El-Zonkoly, "Optimal placement of multidistributed generation units including different load models using particle swarm optimization," IET Gener., Transm., Distrib., vol. 5, no. 7, pp. 760-771, Jul. 2011.

[12] P. Harrison, A. Piccolo, P. Siano, and A. R. Wallace, "Hybrid GA and OPF evaluation of network capacity for distributed generation con-nections," Elect. Power Syst. Res., vol. 78, no. 3, pp. 392-398, Mar. 2008.

[13] Pavlos S. Georgilakis, Nikos D. Hatziargyriou. Optimal Distributed Generation Placement in Power Distribution Networks: Models, Methods, and Future Research. Ieee Transactions On Power Systems, Vol. 28, No. 3, August 2013

[14] Sayyid Mohssen Sajjadi, Mahmoud-Reza Haghifam, Javad Salehi. Simultaneous placement of distributed generation and capacitors in distribution networks considering voltage stability index. Electrical Power and Energy Systems 46 (2013) 366-375.

[15] Mohammad H. Moradi, Arash Zeinalzadeh, Younes Mohammadi, Mohammad Abedini. An efficient hybrid method for solving the optimal sitting and sizing problem of DG and shunt capacitor banks simultaneously based on imperialist competitive algorithm and genetic algorithm. Electrical Power and Energy Systems 54 (2014) 101-111.

[16] M. H. Moradi, M. Abedini, A combination of genetic algorithm and particle swarm optimization for optimal DG location and sizing in distribution systems, Electrical Power and Energy Systems 34 (1) (2012) pp. 66-74

[17] S. Gopiya Naik, D.K.Khatod, M.P.Sharma. Optimal allocation of combined DG and capacitor for real power loss minimization in distribution networks. Electrical Power and Energy Systems 53 (2013) 967-973.

[18] Pinar civicioglu, Backtracking Search Optimization Algorithm for numerical optimization problems, Applied Mathematics and Computation, Vol. 219, 2013, pp. 8121 -8144 .

[19] Paulo M.D, Oliveira D J. The standard backward/forward sweep power flow.

[20] Haque MH. Efficient load flow method for distribution systems with radial or mesh configuration. IEE Proc Gen Trans Distrib 1996; 143(1):33-8.

[21] D. Das. Optimal placement of capacitors in radial distribution system using a Fuzzy-GA method. Electrical Power and Energy Systems 30 (2008) 361-367. 